\title{
Role of cytoglobin, a novel radical scavenger, in stellate cell activation and hepatic fibrosis
}

\author{
Le Thi Thanh Thuy, Hoang Hai, and Norifumi Kawada \\ Department of Hepatology, Graduate School of Medicine, Osaka City University, Osaka, Japan
}

Cytoglobin (Cygb), a stellate cell-specific globin, has recently drawn attention due to its association with liver fibrosis. In the livers of both humans and rodents, Cygb is expressed only in stellate cells and can be utilized as a marker to distinguish stellate cells from hepatic fibroblast-derived myofibroblasts. Loss of Cygb accelerates liver fibrosis and cancer development in mouse models of chronic liver injury including diethylnitrosamine-induced hepatocellular carcinoma, bile duct ligation-induced cholestasis, thioacetamide-induced hepatic fibrosis, and choline-deficient L-amino aciddefined diet-induced non-alcoholic steatohepatitis. This review focuses on the history of research into the role of reactive oxygen species and nitrogen species in liver fibrosis and discusses the current perception of Cygb as a novel radical scavenger with an emphasis on its role in hepatic stellate cell activation and fibrosis. (Clin Mol Hepatol 2020;26:280293)

Keywords: Cytoglobin; Hepatic stellate cells; Fibrosis; Free radical scavengers; Antioxidants

\section{INTRODUCTION}

Liver fibrosis is a wound-healing response to chronic liver diseases (CLDs) and often results in cirrhosis, liver failure, portal hypertension, and hepatocellular carcinoma (HCC). ${ }^{1}$ CLD has various etiologies including alcohol consumption, infectious diseases such as viral hepatitis, exposure to toxins and drugs, persistent autoimmune injury, or chronic conditions of altered metabolism. Whatever its etiology, liver fibrogenesis is a dynamic and highly integrated molecular, tissue, and cellular process that distorts the hepatic architecture, and contributes to the formation of a new biochemical environment in the liver. ${ }^{2}$

The relevance of reactive oxygen species (ROS) to liver fibrosis was first described in 1965 by Comporti et al. ${ }^{3}$ and Ghoshal and Recknage ${ }^{4}$ who reported that liver injury was induced by carbon tetrachloride $\left(\mathrm{CCl}_{4}\right)$ via lipid peroxidation. Two years later, Di Luzio and Hartman ${ }^{5}$ implicated lipid peroxidation in the pathogenesis of ethanol-induced fatty liver. Figure 1 shows the timeline of research on the role of oxidative stress in liver diseases. ${ }^{6-17}$ Almost 50 years have passed, and today oxidative stress is known to be

\footnotetext{
Abbreviations:

$\mathrm{BDL}$, bile duct ligation; $\mathrm{CCl}_{4}$, carbon tetrachloride; $\mathrm{CLD}$, chronic liver disease Cygb, cytoglobin; CYP2E1, cytochrome P450 2E1; GSH, glutathione; Hb, hemoglobin; HCC, hepatocellular carcinoma; HCV, hepatitis C virus; HSCs, hepatic stellate cells; IL, interleukin; iNOS, inducible nitric oxide synthase; IRF, interferon response factor; KC, Kupffer cells; LPS, lipopolysaccharide; Mb, myoglobin; Mn, manganese; NASH, non-alcoholic steatohepatitis; $\mathrm{Ngb}$, neuroglobin; NO, nitric oxide; $\mathrm{NOX}, \mathrm{NADPH}$ oxidase; $\mathrm{O}_{2}^{-}$, superoxide anion; $\mathrm{ONOO}^{-}$, peroxynitrite; PPAR, peroxisome proliferator-activated receptor; RNS, reactive nitrogen species; ROS, reactive oxygen species; SOD, superoxide dismutase; TAA, thioacetamide; TG, transgenic; TNF, tumor necrosis factor; aSMA, a-smooth muscle actin
}

\section{Corresponding author : Norifumi Kawada}

Department of Hepatology, Graduate School of Medicine, Osaka City University, 1-4-3 Asahimachi, Abeno, Osaka 545-8585, Japan

Tel: +81-6-6645-3897, Fax: +81-6-6646-6072

E-mail: kawadanori@med.osaka-cu.ac.jp

https://orcid.org/0000-0002-6392-8311 
Le Thi Thanh Thuy, et al.

Landmark in ROS research in liver diseases

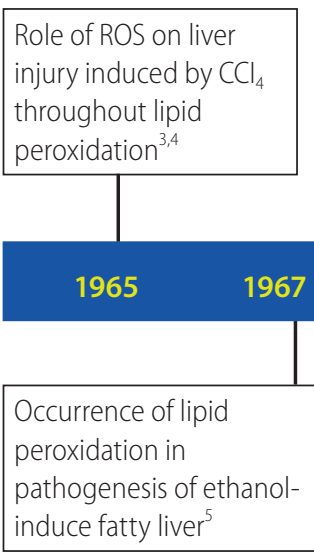

Mechanism of free radicalinduced liver tissue injury ${ }^{6}$

Figure 1. Timeline of research into ROS in liver disease. ROS, reactive oxygen species; $\mathrm{CCl}_{4}$, carbon tetrachloride; NASH, non-alcoholic steatohepatitis.
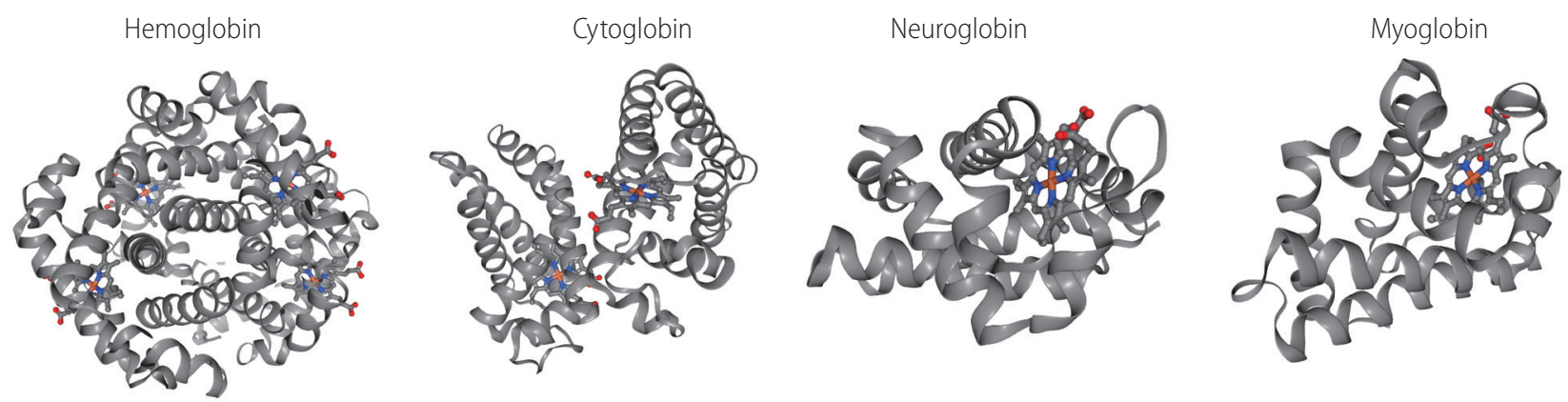

Figure 2. 3D structure of four members of globin family. Human haemoglobin (RCSB Protein Data Bank accession number: $2 \mathrm{HHB}$, tetramer ${ }^{158}$ ), cytoglobin $\left(1 \mathrm{~V} 5 \mathrm{H}\right.$, dimer $\left.{ }^{40}\right)$, neuroglobin $\left(10 \mathrm{~J} 6\right.$, monomer $\left.{ }^{159}\right)$, and myoglobin $\left(3 \mathrm{RGK}\right.$, monomer $\left.{ }^{160}\right)$ are shown with alpha-helices and heme group. Color scheme for the elements: grey for carbon, red for oxygen, blue nitrogen, yellow for sulfur.

related to chronic liver injury and hepatic fibrosis caused by ethanol, ${ }^{18,19} \mathrm{CCl}_{4}{ }^{20}$ as well as non-alcoholic steatohepatitis (NASH), ${ }_{1}^{21}$ nonobese patients with $\mathrm{NASH}_{1}{ }^{22}$ iron overload, ${ }^{23,24}$ and hepatitis C virus (HCV). ${ }^{25}$ Moreover, mitochondrial ROS $^{26}$ mediate metabolic pathway signaling, ${ }^{27-29}$ and their changes affect the development and progression of CLD. ${ }^{30-32}$ The fibrogenic progression of these diseases is associated with a significant decrease in, and/or impairment of, antioxidant defenses such as superoxide dismutase (SOD) 2 activity, ${ }^{33,34}$ or manganese (Mn) SOD. ${ }^{35}$

The recently discovered cytoglobin (Cygb), ${ }^{36}$ which has an antioxidant function, is present in hepatic stellate cells (HSCs), ${ }^{37}$ the main cell type involved in liver fibrosis. In proteomic analyses, Kawada et al. ${ }^{36}$ has found this Cygb protein in rat HSCs and named it as stellate cell activation-associated protein. Later, it was classified as the fourth member of the globin family in mammals, after hemoglobin $(\mathrm{Hb})$, myoglobin $(\mathrm{Mb})$, and neuroglobin
(Ngb), and renamed as Cygb. ${ }^{38}$ Figure 2 showed the 3D structure of these four members of globin family in human. Cygb is a 21$\mathrm{kDa}$ protein consisting of 190 amino acids that shows $25 \%$ identity with vertebrate $\mathrm{Mb}$ and $\mathrm{Hb}$, and $16 \%$ identity with human $\mathrm{Ngb}{ }^{39}$ Moreover, some key residues in the ligand-binding reaction are highly conserved among different species of $\mathrm{Ngb}, \mathrm{Mb}$, and $\mathrm{Hb}$. By contrast, both Cygb and Ngb have unusual features, which are different from traditional pentacoordinated globins such as $\mathrm{Mb}$ and $\mathrm{Hb}$. Spectroscopic studies have shown that Cygb and Ngb contain a hexacoordinated heme iron, to which two his imidazole groups are bound directly in both the deoxyferrous and ferric states ${ }^{40}$ Therefore, exogenous ligands, such as $\mathrm{O}_{2}$ or carbon monoxide, can bind to the iron after displacement of one of his imidazole groups from the axial coordination site. ${ }^{39,41}$ However, like $\mathrm{Mb}$, Cygb exhibits high intrinsic affinity for $\mathrm{O}_{2}{ }^{39,40}$ Cygb contains two cysteines, which might form intramolecular or intermolecular 


\section{CLINICAL and MOLECULAR}

disulfide bridges. ${ }^{42,43}$ Their substitution or reduction diminish Cygb affinity to $\mathrm{O}_{2}$. This indicates that the cellular redox state influences protein structure by $\mathrm{S}$-S bond formation or cleavage, thus affecting $\mathrm{O}_{2}$ binding.

Not only structural but also functional and pathophysiological characterizations of Cygb have been reported. This review highlights the protective role of Cygb in liver fibrosis via its ROS-scavenging function and discusses its future prospects.

\section{CYGB: TISSUE AND CELLULAR DISTRIBUTION}

Cygb is expressed ubiquitously in all vertebrate organs, including the brain, liver, heart, lung, retina, gut, and esophagus. The expression of Cygb in mouse organs was shown in Figure 3. Looking at the liver, Cygb is detected in $\mathrm{HSCs}^{36}$ but not in hepatocytes, Kupffer cells (KCs), endothelial cells, or myofibroblasts. ${ }^{37}$ It is also present in the stromal cells of the red pulp of the spleen. In the kidney, Cygb expression is present in stromal cells along the proximal and distal uriniferous tubules. ${ }^{44}$ It is expressed in fibroblasts, but not in cardiomyocytes in the heart. In the lung, it is found in chondroblasts or stromal cells along alveolar walls. In the thymus, it is present in stromal cells. Interestingly, Cygb is also found in adipose tissue (Fig. 3). A novel expression site is in melanocytes; its absence is associated with the melanocyte-to-melanoma transition. ${ }^{45}$

At the cellular level, Cygb is mainly expressed in fibroblast-related cell lineages such as HSCS, chondroblasts, and osteo- blasts. ${ }^{37,46-52}$ Moreover, it has been found in distinct neuron populations. ${ }^{47,50,53}$ Cytoplasmic and nuclear Cygb localization mainly occurs in neurons. Specific Cygb expression in neurons suggests that the globin may play different roles in this cell population compared to mesenchymal cells. ${ }^{47}$ Some studies have demonstrated that Cygb localizes in macrophages, muscles, ${ }^{54}$ hepatocytes, ${ }^{53}$ and epithelium. ${ }^{53-55}$ However, the discrepancies between the studies on the cell-type and subcellular localization of Cygb might have arisen due to technical issues related to the specificity of the antibodies used, immunodetection methods applied, and endogenous Cygb expression level. ${ }^{56}$

\section{CYGB: A NOVEL RADICAL SCAVENGER}

\section{Impact of radicals in liver fibrosis}

Oxygen free radicals, more generally known as ROS, along with reactive nitrogen species (RNS) are the most important radical species generated in living systems. ${ }^{57}$ ROS and RNS play an important role in the establishment of fibrosis and subsequently in cirrhosis. ${ }^{58}$ In a previous study, human HSCs cultured with human neutrophils stimulated to produce ROS showed evidence of not only oxidative stress but also increased procollagen a1(I) mRNA and protein levels compared to those co-cultured with unstimulated neutrophils. ${ }^{59}$ These effects were inhibited by adding vitamin $E$ or SOD to the culture. By contrast, the intra- and extracellular hydrogen peroxide, lipid peroxidation, and collagen type I levels
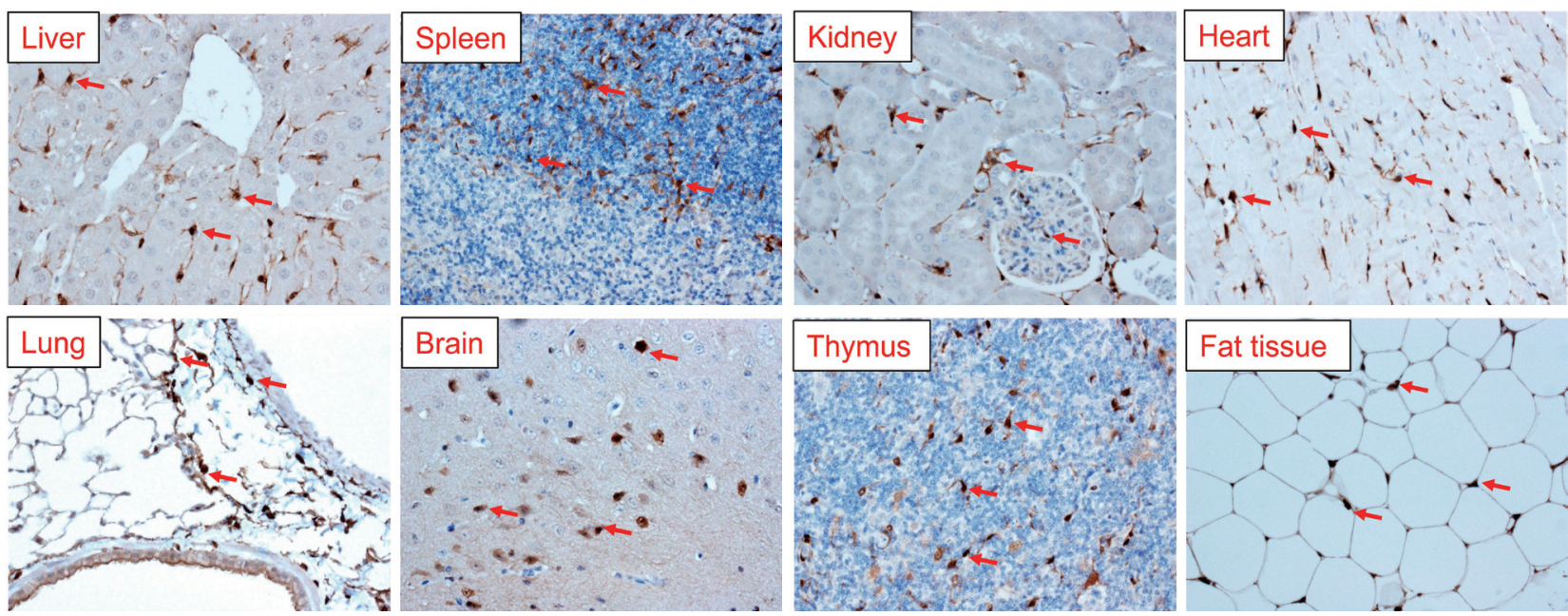

Figure 3. Cygb expression in multiple organs of mice. Immunohistochemical staining of Cygb antibody (our laboratory ${ }^{103}$ ) showing dense Cygb positive cells in all organs. Representative red arrows, Cygb positive cells. Original magnification, ×400. Cygb, cytoglobin. 
Le Thi Thanh Thuy, et al.

Cytoglobin suppresses HSC activation and fibrosis

were increased in HSCs co-cultured with HepG2 cells, which express cytochrome P450 2E1 (CYP2E1). In another study, an increase in collagen production was prevented by antioxidants and a CYP2E1 inhibitor. ${ }^{60}$ Similarly, co-culture with KCs results in activation and proliferation of HSCs, along with increased production of collagen type I and hydrogen peroxide. ${ }^{61}$ Thus, induction of oxidative stress in inflammatory cells, macrophages, and CYP2E1positive hepatoma cells leads to the production of pro-fibrogenic mediators. In patients with alcoholic liver disease and NASH, CYP2E1 plays a critical role in ROS generation ${ }^{62}$ and CYP2E1 is induced by alcohol. ${ }^{63}$ One of the reasons for the increase in the $\mathrm{CY}$ P2E1 protein level during chronic ethanol intake is decreased proteasomal degradation. ${ }^{64}$ A newly discovered host marker of oxidative stress, $3 \beta$-hydroxysterol $\triangle 24$-reductase, an $\mathrm{HCV}$-induced oxidative stress responsive protein, ${ }^{65,66}$ may play a critical role in the pathogenesis of chronic HCV infection and associated liver diseases when aberrantly expressed. ${ }^{67,68}$ Thus, irrespective of etiology, generation of ROS and other free radicals cause oxidative stress in chronic liver injury-induced fibrosis.

Nitrosative stress is a condition in which production of RNS is excessive, exceeding the system's ability to neutralize and eliminate them. ${ }^{69}$ Nitrosative stress acts together with oxidative stress to damage cells. The reaction of nitric oxide (NO) with the superoxide anion $\left(\mathrm{O}_{2}^{-}\right)$results in formation of peroxynitrite $\left(\mathrm{ONOO}^{-}\right)_{1}^{70,71}$ and nitrotyrosine which in turn cause nucleotide modifications in DNA and induce dysfunction and degradation of several functional proteins. ${ }^{72}$ In a study that used an animal model of endotoxemia, plasma S-nitrosothiol and hepatic nitrotyrosine levels were significantly higher in rats with cirrhosis than in control rats, and there was strong positive staining for nitrotyrosine in immunohistochemistry analyses of the livers of rats with cirrhosis. ${ }^{73}$ Large amount of NO can be generated by inducible NO synthase (iNOS) in the liver, via immunological stimuli, such as bacterial lipopolysaccharide (LPS) and inflammatory cytokines, which implicated in many liver diseases, including liver fibrosis. ${ }^{74}$ In human, Koruk et al. ${ }^{75}$ reported that the elevated serum NO level (determination by the stable end products of NO radical, nitrite $\left[\mathrm{NO}^{-}\right]$and nitrate $\left[\mathrm{NO3}^{-}\right]$) in patients with hepatic cirrhosis suggesting NO contributes to the progression of cirrhosis. The levels of NO derivatives, as mentioned above, nitrotyrosine, and nitrosothiols, are also increased in autoimmune hepatitis, ${ }^{76}$ and primary biliary cholangitis. $^{77,78}$ In NASH patients, both iNOS and nitrotyrosine levels are significantly elevated. ${ }^{79}$ These findings suggest a major role for NO in chronic liver injury-associated fibrogenesis.

A causative role for oxidative stress in liver fibrogenesis has been strongly suggested by several reports that supplementation with antioxidants prevents fibrogenic progression. Experimental models of liver fibrosis/cirrhosis have been used to evaluate antioxidant compounds such as polyunsaturated phosphatidylcholine, ${ }^{80}$ peroxisome proliferator-activated receptor (PPAR) a ligand, ${ }^{81}$ ursodeoxycholic acid, ${ }^{82}$ and resveratrol. ${ }^{83-86}$ Clinically, the only drug used to treat acetaminophen overdose patients is the precursor of glutathione (GSH), N-acetylcysteine. ${ }^{87}$ Other antioxidant treatments include GSH, resveratrol, or Mito-TEMPO, a Mn superoxide dismutase mimetic. ${ }^{88,89}$ S-adenosylmethionine, silymarin, and vitamin $\mathrm{E}$ have been tested in liver fibrosis/cirrhosis patients. An effect of vitamin E has been reported in ASH- or NASHinduced fibrosis, where histological findings such as steatosis, inflammation, and fibrosis were improved. ${ }^{90}$ The most promising results were reported from PIVENS trial, ${ }^{91}$ which was performed in 247 patients for 96 months. Vitamin E treatment led to clear histological regression without fibrosis progression. Currently, the ClinicalTrials.gov website lists 14 early and phase I-IV clinical trials of antioxidant therapies for liver cirrhosis. In these studies, vitamins, particularly vitamin $E$, are the most frequently studied antioxidants used as dietary supplements.

\section{CYGB scavenges ROS and RNS}

\section{Cygb holds intrinsic $\mathrm{O}_{2}$-binding capacity}

As a member of the globin family, the heme iron of Cygb has the same affinities for exogenous ligands and the same equilibrium constant for oxygen as Mb. ${ }^{36,39}$ Cygb contributes to intracellular $\mathrm{O}_{2}$ supply, ${ }^{92}$ acting as an $\mathrm{O}_{2}$ reservoir or as a signal transducer in $\mathrm{O}_{2}$-sensing pathways. ${ }^{53,93} \mathrm{~A}$ change in the cellular redox state could promote conformational changes in Cygb and increase $\mathrm{O}_{2}$ release (e.g., the reduction of S-S bridges by reducing agents $\mathrm{H}+$ or nicotinamide adenine dinucleotide). ${ }^{42}$

\section{Cygb scavenges ROS}

Cygb has several roles, including detoxification of ROS, involvement in NO metabolism, protection from apoptosis, and lipid metabolism. ${ }^{93-96}$ Plasma-produced ROS/RNS can oxidize Cygb proteins, leading to a conformational change, thereby enabling access to the heme and facilitating ligand binding. ${ }^{97}$ Interestingly, human Cygb mutants with one or both terminal domains truncated show slightly higher superoxide scavenging activity than wildtype Cygb. ${ }^{98}$ Overexpression of Cygb under conditions of oxidative stress have been found in a number of studies. ${ }^{50,99}$ Its overexpression protected human neuroblastoma SH-SY5Y cells from $\mathrm{H}_{2} \mathrm{O}_{2}$-in- 


\section{CLINCAL and MOLECULAR}

duced cell death ${ }^{100,101}$ and rescues the human neuronal cell line TE671 from pro-oxidant Ro19-8022-induced DNA damage. ${ }^{102}$ Furthermore, in vitro and in vivo overexpression of Cygb in rat HSCs protect these cells against oxidative stress and inhibit their differentiation into an active phenotype. ${ }^{103}$ Therefore, the question is whether oxidative stress is magnified in the absence of Cygb. We generated Cygb-knockout mice and challenged them with various factors that induce liver diseases. First, the mice were treated with 0.05 ppm diethylnitrosamine, an established liver carcinogen, for 36 weeks. Liver tumors occurred in $57.1 \%$ of the knockout mice compared to $0 \%$ of the wild-type mice. In this model, background liver tissues of knockout mice showed marked development of liver fibrosis, augmented inflammatory reactions, and overproduction of $\mathrm{ONOO} \cdot{ }^{-104}$ Second, mice were given a choline-deficient Lamino acid-defined diet for 32 weeks to induce steatohepatitis. Unexpectedly, 100\% of Cygb-knockout mice developed multiple liver tumors, compared to $0 \%$ of the wild-type mice. Again, background liver tissues showed development of liver fibrosis and augmented inflammatory reactions, accompanied by DNA doublestrand breaks ( $\gamma \mathrm{H} 2 \mathrm{AX}$ expression) in hepatocytes. These results suggest a protective role for Cygb against oxidative stress, liver fibrosis, and cancer development in the presence of chronic inflammation. ${ }^{52}$ Recently, Latina et al. ${ }^{105}$ reported that the Cygb gene is transcriptionally regulated by $\triangle N p 63$ in primary epithelial cells (keratinocytes) and in cancer cells (H226, MCF-7) under both normal proliferation conditions (normoxia) and following oxidative stress. Taken together, these reports suggest that, in addition to its function as a gas carrier, Cygb acts as a cytoprotective molecule under hypoxia and oxidative stress.

\section{Nitric oxide scavenger}

Many globins, including Cygb, show NO dioxygenase activity. ${ }^{106-108}$ In the oxy-ferrous state, all human Ngb and Cygb, rice $\mathrm{nsHb}$ (riceHb1), Synechocystis Hb (cyanoglobin, SynHb), and horse heart $\mathrm{Mb}$ rapidly destroy NO in vitro, and Cygb has the highest consumption rate. ${ }^{109}$ At a low $\mathrm{O}_{2}$ level $(0-50 \mathrm{mM})$, Cygb with cellular reductants regulates the $\mathrm{NO}$ consumption rate in response to changes in $\mathrm{O}_{2}$ concentration and is around 500 -fold more sensitive to changes in the $\mathrm{O}_{2}$ level than Mb. ${ }^{110}$ Indeed, the NO dioxygenase activity of Cygb is rapid with or without a disulfide bond; however, binding of the distal histidine following dissociation of the nitrate is affected by the presence or absence of the disulfide bond..$^{111}$ The NO scavenging function of Cygb protects the NOsensitive aconitase, and decreases $\mathrm{ONOO}^{-}$formation. ${ }^{108}$ Cygb plays a critical role in the regulation of vascular tone and blood

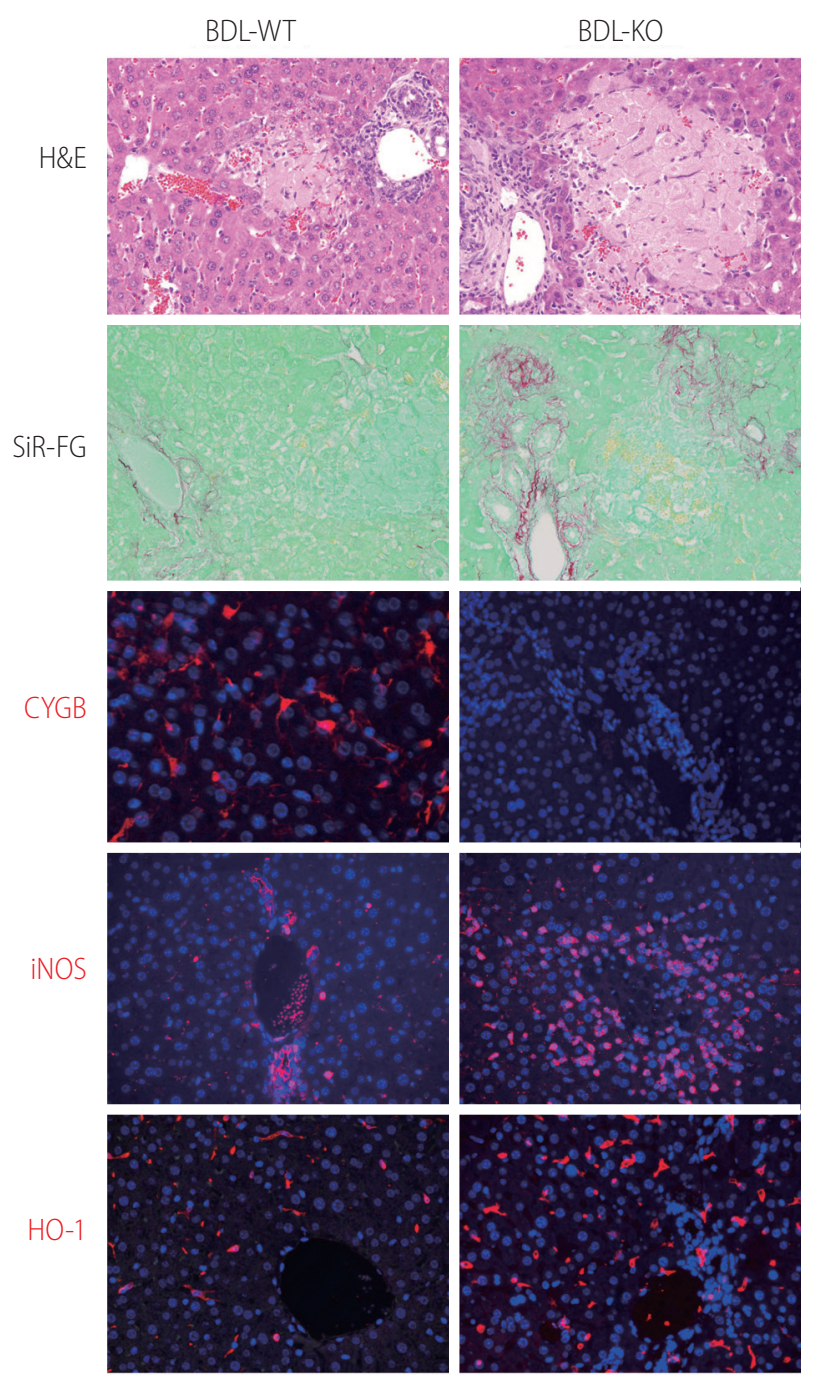

Figure 4. Loss of Cygb promoted bile duct ligation induced liver cholestasis. Bile duct ligation was performed in WT (BDL-WT) and Cygb$\mathrm{KO}(\mathrm{BDL}-\mathrm{KO})$ mice. Liver tissues from 1 week of $\mathrm{BDL}$ stained with $\mathrm{H \& E}$, and Sirius-Red and Fast Green (SiR-FG) showed marked hepatocyte damage and severe fibrosis in KO compared with WT mice. Immunofluorescent staining of Cygb (red) showing the absence of Cygb in KO liver. Both iNOS and HO-1 (red), the markers of RNS and ROS, respectively, revealed strong oxidative stress took place in the KO mice after 24 hours of BDL. DAPI, blue, was used as nuclear counterstain. Original magnification, $\times 400$. H\&E, Hematoxylin and Eosin; Cygb, cytoglobin; iNOS, inducible nitric oxide synthase; RNS, reactive nitrogen species; ROS, reactive oxygen species; DAPI, 4',6-diamidino-2-phenylindole.

pressure via NO metabolism. ${ }^{94}$ Importantly, CYGB is expressed in vessels primarily in differentiated medial vascular smooth muscle cells, where it regulates neointima formation and inhibits apoptosis after injury.112 Moreover, when the Cygb-KO mice were challenged with bile duct ligation (BDL) induced liver cholestasis, liver 
CYTC
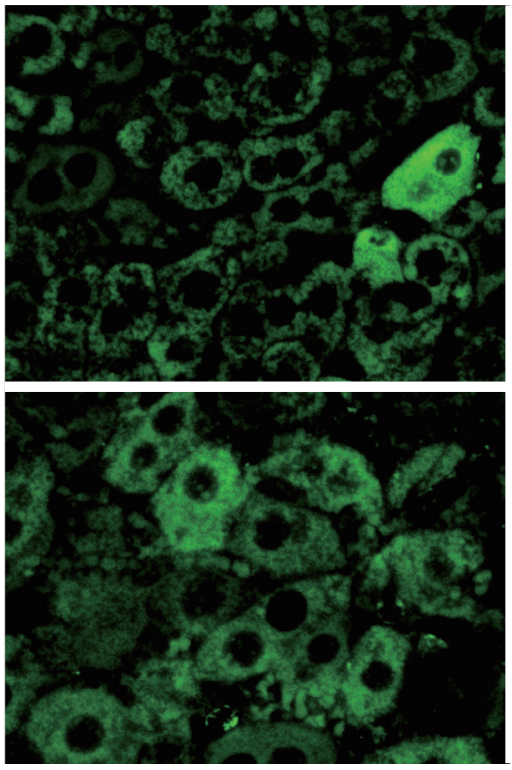

CASP3
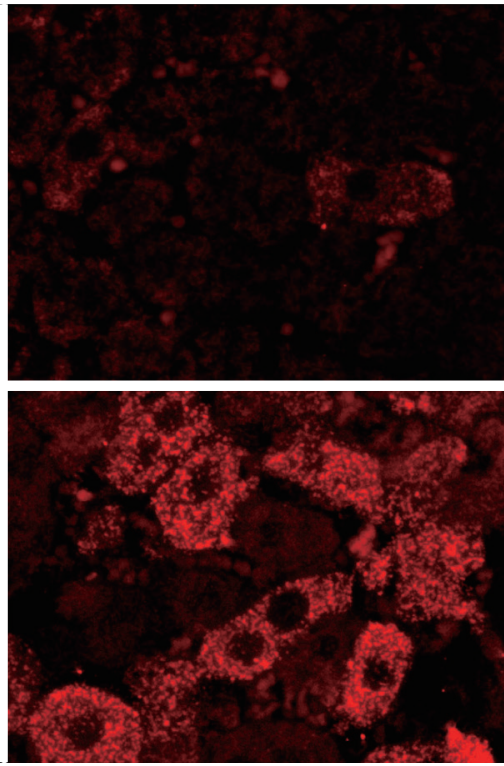

CYT C-CASP3-DAPI
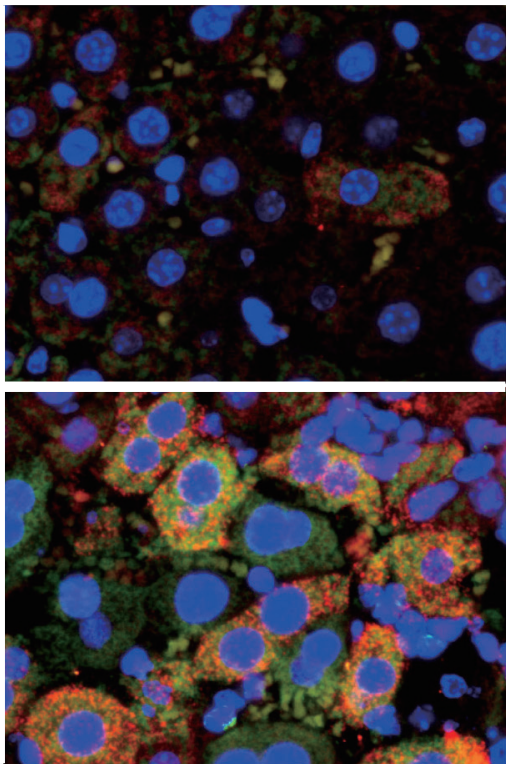

Figure 5. Hepatocyte apoptosis in Cygb-KO liver under BDL. Expression of markers of apoptosis cytochrome C (CYTC) (green) and active + pro Caspase (CASP) 3 (red) after 24 hours of BDL in WT and KO mice. DAPI, blue, was used as nuclear counterstain. Original magnification, $\times 1,200$. BDL, bile duct ligation; Cygb, cytoglobin; DAPI, 4'6-diamidino-2-phenylindole.

injuries including hepatocyte damage, oxidative stress, and fibrosis were massively developed compared to corresponding WT (Fig. 4). This severe liver cholestasis is accompanied by markedly increased apoptosis cell dead as indicated in Figure 5. Furthermore, the levels of nitrite and nitrate in the serum, urine, and liver in Cygb-deficient mice are all significantly elevated. ${ }^{113}$ Interestingly, treatment of NO inhibitor to BDL-treated Cygb-KO mice can ameliorate this cholestasis condition. ${ }^{113}$ Thus, the NO-scavenging function of Cygb is crucial for protecting cells/tissues from NO accumulation.

\section{CYGB SUPPRESSES HSC ACTIVATION AND FIBROSIS DEVELOPMENT}

\section{HSC and hepatic fibrosis}

HSCs reside in the space of Disse, between the basolateral surface of hepatocytes and the anti-luminal side of sinusoidal endothelial cells, ${ }^{114}$ and contain retinoid and lipid droplets. ${ }^{115}$ Under physiological conditions, HSCs exhibit a quiescent phenotype and express neural markers, such as glial fibrillary acidic protein, synemin, synaptophysin, ${ }^{116}$ nerve growth factor receptor $p 75,{ }^{117}$ desmin, CD146, and hepatocyte growth factor. ${ }^{118}$ The notion that HSCs are a major collagen-producing cell type in the normal liver was experimentally verified in 1984 by Senoo et al. ${ }^{119}$ and in 1985 by Friedman et al. ${ }^{120}$ Friedman also pointed out that normal HSCs exhibit not only fibroblastic characteristics but also smooth muscle cell-like features, such as the production of basement membrane collagen (type IV collagen) ${ }^{120}$ and the expression of the intermediate filament protein desmin. ${ }^{121}$ Beyond their role as the major collagen-producing cells, their activation is a key issue in liver fibrosis. ${ }^{122}$ Stimuli such as oxidative stress signals (reactive oxygen intermediates), apoptotic bodies, LPS, and paracrine signals from neighboring cells including KCs, liver sinusoidal endothelial cells, and hepatocytes can trigger HSC activation or transdifferentiation into myofibroblast-like cells that acquire contractile, proinflammatory, and fibrogenic properties. ${ }^{1,123,124}$ The dead or dying hepatocytes as well as leukocytes phagocytosing the cells release inflammatory mediators, damage-associated molecular patterns or danger signals, which initiate and perpetuate a non-infectious "sterile" inflammatory response. Among such mediators, tumor necrosis factor (TNF), interleukin (IL) 6, IL-1 $\beta$, ROS, hedgehog ligands, and nucleotides contribute to the initiation of HSC activation. ${ }^{125-127}$ Other key elements critical for the fibrotic activity in HSCs are NADPH oxidase (NOX) enzymes, in which all NOX1, NOX2, and NOX4 are upregulated in activated HSCs compared to quiescent HSCs. ${ }^{128,129}$ Indeed, the mRNA for the cytoplasmic factor p47phox and the cell membrane proteins NOX2 and NOX1 are 


\section{CLINICAL and MOLECULAR}

\section{HEPATOLOGY}

detected at very low levels in quiescent HSCs by real time Reverse Transcription Polymerase Chain Reaction, while they are highly expressed following HSC activation in culture and in cells freshly isolated from patients with liver fibrosis. ${ }^{130}$

The pathways most involved in HSC activation and deactivation are related to membrane receptor signaling, including transforming growth factor beta (TGF $\beta$ ), which has an autocrine positive feedback loop that drives fibrogenesis via mothers against DPP homolog (SMAD) 2/3, ${ }^{131,132}$ platelet-derived growth factor, a potent chemoattractant induced during initiation of HSC activation that enhances inflammatory and fibrogenic responses, ${ }^{133,134}$ and connective tissue growth factor and epidermal growth factor receptors, which are overexpressed and phosphorylated in activated HSCs. ${ }^{135-138}$ A recent study ${ }^{139}$ identified transcription factors that prevent activation of HSCs and promote fibrosis resolution, including E26 transcription-specific transcription factor (EST1), ETS2, GATA binding protein (GATA4), GATA6, interferon response factor (IRF) 1, and IRF2. In particular, GATA6 and PPARy are required for inactivation of human HSCs and regression of liver fibrosis in mice. ${ }^{139}$ Further analyses of the metabolic changes in HSCs during the initial and chronic phases of fibrosis have provided insight into the metabolic regulation of HSC activation including metabolism of retinol, ${ }^{140,141}$ lipid, ${ }^{142,143}$ nitrogen, ${ }^{144}$ redox biology, ${ }_{1}^{12,145}$ and endoplasmic reticulum stress, ${ }^{146}$ which are important for development of targeted interventions to reverse HSC activation or trigger their apoptosis..$^{147}$ Clinical and experimental studies have demonstrated that the regression of liver fibrosis may be caused by the disappearance of activated HSCs/myofibroblasts by apoptosis, ${ }^{126,148}$ inactivation into a quiescent-like state, ${ }^{149,150}$ or senescence. ${ }^{151,152}$

\section{Cygb regulates HSC activation and fibrogenesis}

The ROS-scavenging function of Cygb is evidenced by its ability to detoxify radicals via reaction with its heme. ${ }^{153}$ In Xu et al., ${ }^{103}$ overexpression of Cygb protected primary rat HSCs against oxidative stress, as assessed by reduced production of malondialdehyde and 4-hydroxynonenal, biomarkers of lipid peroxidation. In Stone et al., ${ }^{154}$ Cygb expression was correlated with a more quiescent phenotype of stellate cells in culture and Cygb was regulated by the extracellular matrix through integrin signaling in a manner dependent on activation of focal adhesion kinase. Consistently, in human liver tissues damaged by HCV infection at various fibrosis stages, the number of Cygb-positive cells decreases with fibrosis progression. ${ }^{37}$ Interestingly, Cygb is abundant in HSCs but absent in myofibroblasts rich in fibrotic septum and positive for a-smooth muscle actin (aSMA), fubulin-2 and Thy-1. ${ }^{37}$ In other fibrosis conditions, overexpression of Cygb in human tendon fibroblasts decreases the expression levels of fibronectin, collagen I, collagen III, TGF- $\beta 1$ and hypoxia-inducible factor 1, suggesting an antiscarring effect of Cygb post-glaucoma surgery. ${ }^{155}$ Randi et al. ${ }^{156}$ demonstrated abundant Cygb expression in human podocyte lines and that it has an antioxidant effect in chronic renal diseases.

We have generated, for the first time, a new transgenic (TG) mouse line in which both Cygb and mCherry reporter gene expression is controlled under the native Cygb gene promoter. $\mathrm{Ad}$ ministration of a single dose $(50 \mathrm{mg} / \mathrm{kg}$ ) of thioacetamide (TAA) in Cygb-TG mice resulted in lower levels of serum alanine aminotransferase and oxidative stress than those of wild-type mice. At 10 weeks of TAA administration, Cygb-TG livers exhibited reduced neutrophil accumulation, cytokine expression and fibro-

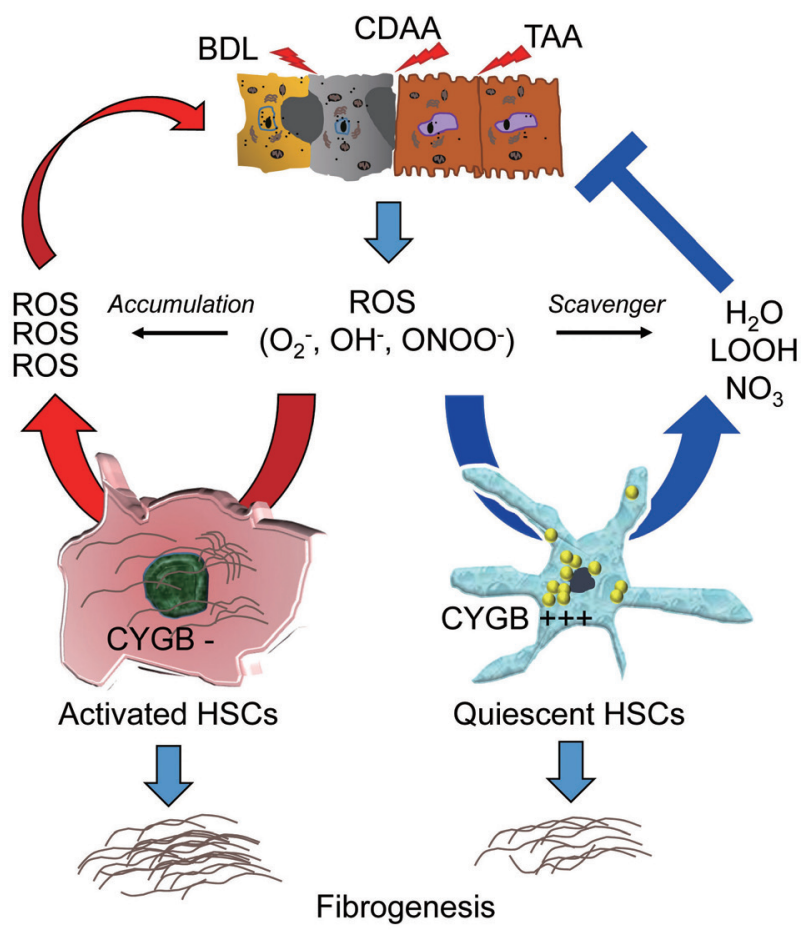

Figure 6. ROS-scavenging function of Cygb in liver injury. Liver injury induced by, for instance, bile duct ligation (BDL), choline deficient amino acid-define diet (CDAA), or thioacetamide (TAA) released ROS including $\mathrm{O}_{2}^{-}, \mathrm{OH}^{-}, \mathrm{ONOO}^{-}$radicals which can induce $\mathrm{HSCs}$ activation, and fibrosis development. In the absence of Cygb (Cygb-), these radicals have not been scavenged, thus promote HSCs activation and magnified both liver damage and fibrosis. This cycle is suppressed when Cygb is overexpressed ( $\mathrm{Cygb+++}$ ) and scavenges $\mathrm{ROS}$ to $\mathrm{H}_{2} \mathrm{O}, \mathrm{LOOH}$, or $\mathrm{NO}_{3}$. ROS, reactive oxygen species; $\mathrm{ONOO}^{-}$, peroxynitrite; $\mathrm{LOOH}$, lipid hydroperoxides; Cygb, cytoglobin; HSCs, hepatic stellate cells. 
sis, and high levels of quiescent HSCS. ${ }^{157} \mathrm{HSCs}$ in the absence of Cygb (HSCs ${ }^{\text {Cygb-null }}$ ) become enlarged with a developed aSMA network after 7 days in culture and lose cellular lipid droplets more rapidly than $\mathrm{HSCS}^{\text {Cygb-wild }}$. Moreover, $\mathrm{HSCS}^{\text {Cygb-null }}$ shows a pre-activated phenotype with increased oxidative stress and markedly elevated expression of cytokines and chemokinse such as IL-6, TNFa, IL-1 $\beta$, chemokine (C-X-C motif) ligand-1, -2, and chemokine ligand-2, $-3,-4 .{ }^{52}$ By contrast, primary HSCs isolated from CygbTG mice ( $\mathrm{HSC}^{\mathrm{Cygb}-\mathrm{TG}}$ ) exhibit a significantly decreased aSMA, collagen 1 11 , and TGF- $\beta 3$ after 4 days in culture compared to WT cells. $\mathrm{HSCS}^{\text {Cygb-TG }}$ are resistant to $\mathrm{H}_{2} \mathrm{O}_{2}$-induced aSMA expression. ${ }^{157}$ Thus, cell-specific overexpression of Cygb attenuates HSC activation and protects mice against TAA-induced liver fibrosis presumably by maintaining quiescence of HSCs. Figure 6 shows the role of Cygb in liver fibrosis.

\section{CONCLUSION AND FUTURE DIRECTION}

More than 600 clinical trials of antifibrotic drugs are underway (http://www.ClinicalTrials.gov). One reason for this is the recognition of the central role of HSCs in liver fibrosis. Promising approaches to removing fibrogenic cells are being evaluated, including drug-delivery systems targeting activated HSCs. In parallel, antioxidant therapy has been targeted by the recovery of antioxidant enzymes/compounds and by reducing the production of ROS and RNS. Furthermore, a number of recent studies have explored the protective role of Cygb in hepatic fibrosis, which is mediated by inactivation of HSCs. Hopefully, the best drug for anti-fibrotic therapy will be discovered in the near future.

\section{Authors' contributions}

LTTT, HH, and NK contributed to the literature review, and manuscript preparation.

\section{Acknowledgements}

NK was supported by a Grant-in-Aid for Scientific Research from the Japan Society for the Promotion of Science (JSPS) through Grant No. J192640002 (2019-2022) and by the Japan Agency for Medical Research and Development (AMED, 20192022).

LTTT was supported by a Grant-in-Aid for Scientific Research from JSPS through Grant No. J192640023 (2019-2022), and by the GILEAD Science Research Scholar Program in Liver Diseases Asia (2019-2021).

\section{Conflicts of Interest}

The authors have no conflicts to disclose.

\section{REFERENCES}

1. Friedman SL. Mechanisms of hepatic fibrogenesis. Gastroenterology 2008;134:1655-1669.

2. Pinzani M, Rombouts K. Liver fibrosis: from the bench to clinical targets. Dig Liver Dis 2004;36:231-242.

3. Comporti M, Saccocci C, Dianzani MU. Effect of $\mathrm{CCl}-4$ in vitro and in vivo on lipid peroxidation of rat liver homogenates and subcellular fractions. Enzymologia 1965;29:185-204.

4. Ghoshal AK, Recknagel RO. Positive evidence of acceleration of lipoperoxidation in rat liver by carbon tetrachloride: in vitro experiments. Life Sci (1962) 1965;4:1521-1530.

5. Di Luzio NR, Hartman AD. Role of lipid peroxidation in the pathogenesis of the ethanol-induced fatty liver. Fed Proc 1967;26:14361442.

6. Slater TF. Free-radical mechanisms in tissue injury. Biochem J 1984;222:1-15.

7. Albano E, Poli G, Tomasi A, Bini A, Vannini V, Dianzani MU. Toxicity of 1,2-dibromoethane in isolated hepatocytes: role of lipid peroxidation. Chem Biol Interact 1984;50:255-265.

8. Albano E, Bellomo G, Carini R, Biasi F, Poli G, Dianzani MU. Mechanisms responsible for carbon tetrachloride-induced perturbation of mitochondrial calcium homeostasis. FEBS Lett 1985;192:184188.

9. Albano E, Tomasi A, Goria-Gatti L, Poli G, Vannini V, Dianzani MU. Free radical metabolism of alcohols by rat liver microsomes. Free Radic Res Commun 1987;3:243-249.

10. Poli G, Albano E, Dianzani MU. The role of lipid peroxidation in liver damage. Chem Phys Lipids 1987;45:117-142.

11. Nordmann $R$, Ribière $C$, Rouach $H$. Implication of free radical mechanisms in ethanol-induced cellular injury. Free Radic Biol Med 1992;12:219-240.

12. Nanji AA, Zhao S, Sadrzadeh SM, Dannenberg AJ, Tahan SR, Waxman DJ. Markedly enhanced cytochrome P450 2E1 induction and lipid peroxidation is associated with severe liver injury in fish oilethanol-fed rats. Alcohol Clin Exp Res 1994;18:1280-1285.

13. Clot $\mathrm{P}$, Tabone $\mathrm{M}$, Aricò $\mathrm{S}$, Albano E. Monitoring oxidative damage in patients with liver cirrhosis and different daily alcohol intake. Gut 1994;35:1637-1643.

14. Aleynik SI, Leo MA, Aleynik MK, Lieber CS. Increased circulating products of lipid peroxidation in patients with alcoholic liver disease. Alcohol Clin Exp Res 1998;22:192-196.

15. Meagher EA, Barry OP, Burke A, Lucey MR, Lawson JA, Rokach J, 
et al. Alcohol-induced generation of lipid peroxidation products in humans. J Clin Invest 1999;104:805-813.

16. Niemelä O, Parkkila S, Ylä-Herttuala S, Halsted C, Witztum JL, Lanca $A$, et al. Covalent protein adducts in the liver as a result of ethanol metabolism and lipid peroxidation. Lab Invest 1994;70:537546.

17. Bedossa P, Houglum K, Trautwein C, Holstege A, Chojkier M. Stimulation of collagen alpha $1(\mathrm{I})$ gene expression is associated with lipid peroxidation in hepatocellular injury: a link to tissue fibrosis? Hepatology 1994;19:1262-1271.

18. Niemelä O, Parkkila S, Ylä-Herttuala S, Villanueva J, Ruebner B, Halsted $\mathrm{CH}$. Sequential acetaldehyde production, lipid peroxidation, and fibrogenesis in micropig model of alcohol-induced liver disease. Hepatology 1995;22(4 Pt 1):1208-1214.

19. Kamimura S, Gaal K, Britton RS, Bacon BR, Triadafilopoulos G, Tsukamoto H. Increased 4-hydroxynonenal levels in experimental alcoholic liver disease: association of lipid peroxidation with liver fibrogenesis. Hepatology 1992;16:448-453.

20. Castillo T, Koop DR, Kamimura S, Triadafilopoulos G, Tsukamoto H. Role of cytochrome P-450 2E1 in ethanol-, carbon tetrachlorideand iron-dependent microsomal lipid peroxidation. Hepatology 1992;16:992-996.

21. Lieber CS. Role of oxidative stress and antioxidant therapy in alcoholic and nonalcoholic liver diseases. Adv Pharmacol 1997;38:601628.

22. Musso G, Gambino R, De Michieli F, Cassader M, Rizzetto M, Durazzo $M$, et al. Dietary habits and their relations to insulin resistance and postprandial lipemia in nonalcoholic steatohepatitis. Hepatology 2003;37:909-916.

23. Gualdi R, Casalgrandi G, Montosi G, Ventura E, Pietrangelo A. Excess iron into hepatocytes is required for activation of collagen type I gene during experimental siderosis. Gastroenterology 1994;107:1118-1124.

24. Pietrangelo A, Gualdi R, Casalgrandi G, Geerts A, De Bleser $P$, Montosi $G$, et al. Enhanced hepatic collagen type I mRNA expression into fat-storing cells in a rodent model of hemochromatosis. Hepatology 1994;19:714-721.

25. Farinati F, Cardin R, D'Errico A, De Maria N, Naccarato R, Cecchetto $A$, et al. Hepatocyte proliferative activity in chronic liver damage as assessed by the monoclonal antibody MIB1 Ki67 in archival material: the role of etiology, disease activity, iron, and lipid peroxidation. Hepatology 1996;23:1468-1475.

26. Mansouri A, Gattolliat CH, Asselah T. Mitochondrial dysfunction and signaling in chronic liver diseases. Gastroenterology 2018;155:629-647.

27. Win S, Than TA, Kaplowitz N. Hepatic mitochondrial Sab (SH3BP5) plays a pivotal role in sustained JNK activation and steatohepatitis in diet-induced NASH. Hepatology 2016;64:128A.
28. Kang SW, Haydar G, Taniane C, Farrell G, Arias IM, LippincottSchwartz J, et al. AMPK activation prevents and reverses druginduced mitochondrial and hepatocyte injury by promoting mitochondrial fusion and function. PLoS One 2016;11:e0165638.

29. Fiorese CJ, Schulz AM, Lin YF, Rosin N, Pellegrino MW, Haynes CM. The transcription factor ATF5 mediates a mammalian mitochondrial UPR. Curr Biol 2016;26:2037-2043.

30. Du K, Ramachandran A, McGill MR, Mansouri A, Asselah T, Farhood $A$, et al. Induction of mitochondrial biogenesis protects against acetaminophen hepatotoxicity. Food Chem Toxic 2017;108(Pt A):339-350.

31. Fisicaro P, Barili V, Montanini B, Acerbi G, Ferracin M, Guerrieri $F$, et al. Targeting mitochondrial dysfunction can restore antiviral activity of exhausted HBV-specific CD8 T cells in chronic hepatitis B. Nat Med 2017;23:327-336.

32. Khan M, Syed GH, Kim SJ, Siddiqui A. Mitochondrial dynamics and viral infections: a close nexus. Biochim Biophys Acta 2015;1853(10 Pt B):2822-2833.

33. von Montfort C, Matias N, Fernandez A, Fucho R, Conde de la Rosa L, Martinez-Chantar ML, et al. Mitochondrial GSH determines the toxic or therapeutic potential of superoxide scavenging in steatohepatitis. J Hepatol 2012;57:852-859.

34. Demicheli V, Quijano C, Alvarez B, Radi R. Inactivation and nitration of human superoxide dismutase (SOD) by fluxes of nitric oxide and superoxide. Free Radic Biol Med 2007;42:1359-1368.

35. MacMillan-Crow LA, Cruthirds DL. Invited review: manganese superoxide dismutase in disease. Free Radical Research 2001;34:325336.

36. Kawada N, Kristensen DB, Asahina K, Nakatani K, Minamiyama Y, Seki $S$, et al. Characterization of a stellate cell activation-associated protein (STAP) with peroxidase activity found in rat hepatic stellate cells. J Biol Chem 2001;276:25318-25323.

37. Motoyama H, Komiya T, Thuy le TT, Tamori A, Enomoto M, Mori-

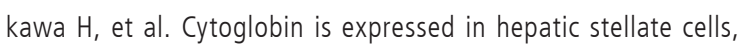
but not in myofibroblasts, in normal and fibrotic human liver. Lab Invest 2014;94:192-207.

38. Burmester T, Ebner B, Weich B, Hankeln T. Cytoglobin: a novel globin type ubiquitously expressed in vertebrate tissues. Mol Biol Evol 2002;19:416-421.

39. Sawai H, Kawada N, Yoshizato K, Nakajima H, Aono S, Shiro Y. Characterization of the heme environmental structure of cytoglobin, a fourth globin in humans. Biochemistry 2003;42:5133-5142.

40. Sugimoto H, Makino M, Sawai H, Kawada N, Yoshizato K, Shiro Y. Structural basis of human cytoglobin for ligand binding. J Mol Biol 2004;339:873-885.

41. Trent JT 3rd, Watts RA, Hargrove MS. Human neuroglobin, a hexacoordinate hemoglobin that reversibly binds oxygen. J Biol Chem 2001;276:30106-30110. 
42. Hamdane D, Kiger L, Dewilde S, Green BN, Pesce A, Uzan J, et al. The redox state of the cell regulates the ligand binding affinity of human neuroglobin and cytoglobin. J Biol Chem 2003;278:5171351721.

43. Lechauve C, Chauvierre C, Dewilde S, Moens L, Green BN, Marden $M C$, et al. Cytoglobin conformations and disulfide bond formation. FEBS J 2010;277:2696-2704.

44. Nakatani K, Okuyama H, Shimahara Y, Saeki S, Kim DH, Nakajima $Y$, et al. Cytoglobin/STAP, its unique localization in splanchnic fibroblast-like cells and function in organ fibrogenesis. Lab Invest 2004;84:91-101.

45. Fujita Y, Koinuma S, De Velasco MA, Bolz J, Togashi Y, Terashima $M$, et al. Melanoma transition is frequently accompanied by a loss of cytoglobin expression in melanocytes: a novel expression site of cytoglobin. PLoS One 2014;9:e94772.

46. Nakatani K, Okuyama H, Shimahara Y, Saeki S, Kim DH, Nakajima $Y$, et al. Cytoglobin/STAP, its unique localization in splanchnic fibroblast-like cells and function in organ fibrogenesis. Lab Invest 2004;84:91-101.

47. Schmidt M, Gerlach F, Avivi A, Laufs T, Wystub S, Simpson JC, et al. Cytoglobin is a respiratory protein in connective tissue and neurons, which is up-regulated by hypoxia. J Biol Chem 2004;279:8063-8069.

48. Tateaki Y, Ogawa T, Kawada N, Kohashi T, Arihiro K, Tateno C, et al. Typing of hepatic nonparenchymal cells using fibulin-2 and cytoglobin/STAP as liver fibrogenesis-related markers. Histochem Cell Biol 2004;122:41-49.

49. Schmidt M, Laufs T, Reuss S, Hankeln T, Burmester T. Divergent distribution of cytoglobin and neuroglobin in the murine eye. Neurosci Lett 2005;374:207-211.

50. Mammen PP, Shelton JM, Ye Q, Kanatous SB, McGrath AJ, Richardson JA, et al. Cytoglobin is a stress-responsive hemoprotein expressed in the developing and adult brain. J Histoche Cytochem 2006;54:1349-1361.

51. Avivi A, Gerlach F, Joel A, Reuss S, Burmester T, Nevo E, et al. Neuroglobin, cytoglobin, and myoglobin contribute to hypoxia adaptation of the subterranean mole rat Spalax. Proc Natl Acad Sci U S A 2010;107:21570-21575.

52. Thuy le TT, Matsumoto $Y$, Thuy TT, Hai H, Suoh M, Urahara $Y$, et al. Cytoglobin deficiency promotes liver cancer development from hepatosteatosis through activation of the oxidative stress pathway. Am J Pathol 2015;185:1045-1060.

53. Geuens E, Brouns I, Flamez D, Dewilde S, Timmermans JP, Moens L. A globin in the nucleus! J Biol Chem 2003;278:30417-30420.

54. Shigematsu A, Adachi Y, Matsubara J, Mukaide H, Koike-Kiriyama N, Minamino K, et al. Analyses of expression of cytoglobin by immunohistochemical studies in human tissues. Hemoglobin 2008:32:287-296.
55. Emara M, Turner AR, Allalunis-Turner J. Hypoxic regulation of cytoglobin and neuroglobin expression in human normal and tumor tissues. Cancer Cell Int 2010;10:33.

56. Oleksiewicz U, Liloglou T, Field JK, Xinarianos G. Cytoglobin: biochemical, functional and clinical perspective of the newest member of the globin family. Cell Mol Life Sci 2011;68:3869-3883.

57. Valko M, Izakovic M, Mazur M, Rhodes CJ, Telser J. Role of oxygen radicals in DNA damage and cancer incidence. Mol Cell Biochem 2004;266:37-56.

58. Muriel P, Gordillo KR. Role of oxidative stress in liver health and disease. Oxid Med Cell Longev 2016;2016:9037051.

59. Casini A, Ceni E, Salzano R, Biondi P, Parola M, Galli A, et al. Neutrophil-derived superoxide anion induces lipid peroxidation and stimulates collagen synthesis in human hepatic stellate cells: role of nitric oxide. Hepatology 1997;25:361-367.

60. Nieto N, Friedman SL, Cederbaum Al. Cytochrome P450 2E1derived reactive oxygen species mediate paracrine stimulation of collagen I protein synthesis by hepatic stellate cells. J Biol Chem 2002;277:9853-9864.

61. Nieto N. Oxidative-stress and IL-6 mediate the fibrogenic effects of [corrected] Kupffer cells on stellate cells. Hepatology 2006:44:1487-1501.

62. Bell LN, Temm CJ, Saxena R, Vuppalanchi R, Schauer P, Rabinovitz $M$, et al. Bariatric surgery-induced weight loss reduces hepatic lipid peroxidation levels and affects hepatic cytochrome P-450 protein content. Ann Surg 2010;251:1041-1048.

63. Leung TM, Nieto N. CYP2E1 and oxidant stress in alcoholic and non-alcoholic fatty liver disease. J Hepatol 2013;58:395-398.

64. Gonzalez FJ. The 2006 Bernard B. Brodie Award Lecture. Cyp2e1 Drug Metab Dispo 2007;35:1-8.

65. Saito M, Kohara M, Tsukiyama-Kohara K. Hepatitis C virus promotes expression of the $3 \beta$-hydroxysterol $\delta 24$-reductase through Sp1. J Med Virol 2012;84:733-746.

66. Takano T, Tsukiyama-Kohara K, Hayashi M, Hirata Y, Satoh M, Tokunaga $Y$, et al. Augmentation of DHCR24 expression by hepatitis $C$ virus infection facilitates viral replication in hepatocytes. J Hepatol 2011;55:512-521.

67. Saito M, Takano T, Nishimura T, Kohara M, Tsukiyama-Kohara K. $3 \beta$-hydroxysterol $\delta 24$-reductase on the surface of hepatitis $C$ virusrelated hepatocellular carcinoma cells can be a target for molecular targeting therapy. PLoS One 2015;10:e0124197.

68. Rebbani K, Tsukiyama-Kohara K. HCV-induced oxidative stress: battlefield-winning strategy. Oxid Med Cell Longev 2016;2016: 7425628.

69. Ridnour LA, Thomas DD, Mancardi D, Espey MG, Miranda KM, Paolocci N, et al. The chemistry of nitrosative stress induced by nitric oxide and reactive nitrogen oxide species. Putting perspective on stressful biological situations. Biol Chem 2004;385:1-10. 
70. Squadrito GL, Pryor WA. Oxidative chemistry of nitric oxide: the roles of superoxide, peroxynitrite, and carbon dioxide. Free Radic Biol Med 1998;25:392-403.

71. Dröge W. Free radicals in the physiological control of cell function. Physiol Rev 2002;82:47-95.

72. Fujita K, Nozaki Y, Yoneda M, Wada K, Takahashi H, Kirikoshi H, et al. Nitric oxide plays a crucial role in the development/progression of nonalcoholic steatohepatitis in the choline-deficient, I-amino acid-defined diet-fed rat model. Alcohol Clin Exp Res 2010;34 Suppl 1:S18-S24.

73. Ottesen LH, Harry D, Frost M, Davies S, Khan K, Halliwell B, et al. Increased formation of $S$-nitrothiols and nitrotyrosine in cirrhotic rats during endotoxemia. Free Radic Biol Med 2001;31:790-798.

74. Iwakiri Y. Nitric oxide in liver fibrosis: the role of inducible nitric oxide synthase. Clin Mol Hepatol 2015;21:319-325.

75. Koruk M, Aksoy H, Akçay F, Onuk MD. Antioxidant capacity and nitric oxide in patients with hepatic cirrhosis. Ann Clin Lab Sci 2002;32:252-256.

76. Beyazit Y, Efe C, Tanoglu A, Purnak T, Sayilir A, Taskiran I, et al. Nitric oxide is a potential mediator of hepatic inflammation and fibrogenesis in autoimmune hepatitis. Scand J Gastroenterol 2015;50:204-210.

77. Grattagliano I, Calamita G, Cocco T, Wang DQ, Portincasa P. Pathogenic role of oxidative and nitrosative stress in primary biliary cirrhosis. World J Gastroenterol 2014;20:5746-5759.

78. Sanz-Cameno P, Medina J, García-Buey L, García-Sánchez A, Borque MJ, Martín-Vílchez $S$, et al. Enhanced intrahepatic inducible nitric oxide synthase expression and nitrotyrosine accumulation in primary biliary cirrhosis and autoimmune hepatitis. J Hepatol 2002;37:723-729.

79. Muriel P. Role of free radicals in liver diseases. Hepatol Int 2009;3:526-536.

80. Lieber CS, Robins SJ, Li J, DeCarli LM, Mak KM, Fasulo JM, et al. Phosphatidylcholine protects against fibrosis and cirrhosis in the baboon. Gastroenterology 1994;106:152-159.

81. Toyama T, Nakamura H, Harano Y, Yamauchi N, Morita A, Kirishima $T$, et al. PPARalpha ligands activate antioxidant enzymes and suppress hepatic fibrosis in rats. Biochem Biophys Res Commun 2004;324:697-704.

82. Serviddio G, Pereda J, Pallardó FV, Carretero J, Borras C, Cutrin J, et al. Ursodeoxycholic acid protects against secondary biliary cirrhosis in rats by preventing mitochondrial oxidative stress. Hepatology 2004;39:711-720.

83. Kawada N, Seki S, Inoue M, Kuroki T. Effect of antioxidants, resveratrol, quercetin, and $\mathrm{N}$-acetylcysteine, on the functions of cultured rat hepatic stellate cells and Kupffer cells. Hepatology 1998;27:1265-1274.

84. Di Pascoli M, Diví M, Rodríguez-Vilarrupla A, Rosado E, Gracia-
Sancho J, Vilaseca M, et al. Resveratrol improves intrahepatic endothelial dysfunction and reduces hepatic fibrosis and portal pressure in cirrhotic rats. J Hepatol 2013;58:904-910.

85. Lee ES, Shin MO, Yoon S, Moon JO. Resveratrol inhibits dimethylnitrosamine-induced hepatic fibrosis in rats. Arch Pharm Res 2010;33:925-932.

86. Chan CC, Cheng LY, Lin CL, Huang YH, Lin HC, Lee FY. The protective role of natural phytoalexin resveratrol on inflammation, fibrosis and regeneration in cholestatic liver injury. Mol Nutr Food Res 2011;55:1841-1849.

87. Knight TR, Ho YS, Farhood A, Jaeschke H. Peroxynitrite is a critical mediator of acetaminophen hepatotoxicity in murine livers: protection by glutathione. J Pharmacol Exp Ther 2002;303:468-475.

88. Du K, Farhood A, Jaeschke H. Mitochondria-targeted antioxidant Mito-TEMPO protects against acetaminophen hepatotoxicity. Arch Toxicol 2017;91:761-773.

89. Lv H, Hong L, Tian Y, Yin C, Zhu C, Feng H. Corilagin alleviates acetaminophen-induced hepatotoxicity via enhancing the AMPK/ GSK3ß-Nrf2 signaling pathway. Cell Commun Signal 2019;17:2.

90. Hasegawa T, Yoneda M, Nakamura K, Makino I, Terano A. Plasma transforming growth factor-beta1 level and efficacy of alphatocopherol in patients with non-alcoholic steatohepatitis: a pilot study. Aliment Pharmacol Ther 2001;15:1667-1672.

91. Sanyal AJ, Chalasani N, Kowdley KV, McCullough A, Diehl AM, Bass NM, et al. Pioglitazone, vitamin $E$, or placebo for nonalcoholic steatohepatitis. N Engl J Med 2010;362:1675-1685.

92. Trent JT 3rd, Hargrove MS. A ubiquitously expressed human hexacoordinate hemoglobin. J Biol Chem 2002;277:19538-19545.

93. Hankeln T, Ebner B, Fuchs C, Gerlach F, Haberkamp M, Laufs TL, et al. Neuroglobin and cytoglobin in search of their role in the vertebrate globin family. J Inorg Biochem 2005;99:110-119.

94. Liu X, El-Mahdy MA, Boslett J, Varadharaj S, Hemann C, Abdelghany $T M$, et al. Cytoglobin regulates blood pressure and vascular tone through nitric oxide metabolism in the vascular wall. Nat Commun 2017;8:14807.

95. Zhang S, Li X, Jourd'heuil FL, Qu S, Devejian N, Bennett E, et al. Cytoglobin promotes cardiac progenitor cell survival against oxidative stress via the upregulation of the NFkB/iNOS signal pathway and nitric oxide production. Sci Rep 2017;7:10754.

96. Thuy Le TT, Hai NT, Hai H, Kawada N. Pathophysiological role of cytoglobin, the fourth globin in mammals, in liver diseases. Histol Histopathol 2016;31:257-267.

97. De Backer J, Razzokov J, Hammerschmid D, Mensch C, Hafideddine $Z$, Kumar $N$, et al. The effect of reactive oxygen and nitrogen species on the structure of cytoglobin: a potential tumor suppressor. Redox Biol 2018;19:1-10.

98. Hanai S, Tsujino H, Yamashita T, Torii R, Sawai H, Shiro Y, et al. Roles of $\mathrm{N}$ - and $\mathrm{C}$-terminal domains in the ligand-binding proper- 
Le Thi Thanh Thuy, et al.

Cytoglobin suppresses HSC activation and fibrosis

ties of cytoglobin. J Inorg Biochem 2018;179:1-9

99. Li D, Chen XQ, Li WJ, Yang YH, Wang JZ, Yu AC. Cytoglobin upregulated by hydrogen peroxide plays a protective role in oxidative stress. Neurochem Res 2007;32:1375-1380.

100. Fordel E, Thijs L, Martinet W, Lenjou M, Laufs T, Van Bockstaele D, et al. Neuroglobin and cytoglobin overexpression protects human SH-SY5Y neuroblastoma cells against oxidative stress-induced cell death. Neurosci Lett 2006;410:146-151.

101. Fordel E, Thijs L, Martinet W, Schrijvers D, Moens L, Dewilde S. Anoxia or oxygen and glucose deprivation in SH-SY5Y cells: a step closer to the unraveling of neuroglobin and cytoglobin functions. Gene 2007;398:114-122.

102. Hodges NJ, Innocent N, Dhanda S, Graham M. Cellular protection from oxidative DNA damage by over-expression of the novel globin cytoglobin in vitro. Mutagenesis 2008;23:293-298.

103. Xu R, Harrison PM, Chen M, Li L, Tsui TY, Fung PC, et al. Cytoglobin overexpression protects against damage-induced fibrosis. Mol Ther 2006;13:1093-1100.

104. Thuy le TT, Morita T, Yoshida K, Wakasa K, lizuka M, Ogawa T, et al. Promotion of liver and lung tumorigenesis in DEN-treated cytoglobin-deficient mice. Am J Pathol 2011;179:1050-1060.

105. Latina $A$, Viticchiè $G$, Lena AM, Piro MC, Annicchiarico-Petruzzelli $M$, Melino $G$, et al. $\triangle N p 63$ targets cytoglobin to inhibit oxidative stress-induced apoptosis in keratinocytes and lung cancer. Oncogene 2016;35:1493-1503.

106. Gardner PR, Gardner AM, Brashear WT, Suzuki T, Hvitved AN, Setchell KD, et al. Hemoglobins dioxygenate nitric oxide with high fidelity. J Inorg Biochem 2006;100:542-550.

107. Vinogradov SN, Moens L. Diversity of globin function: enzymatic, transport, storage, and sensing. J Biol Chem 2008;283:8773-8777.

108. Gardner AM, Cook MR, Gardner PR. Nitric-oxide dioxygenase function of human cytoglobin with cellular reductants and in rat hepatocytes. J Biol Chem 2010;285:23850-23857.

109. Smagghe BJ, Trent JT 3rd, Hargrove MS. NO dioxygenase activity in hemoglobins is ubiquitous in vitro, but limited by reduction in vivo. PLoS One 2008;3:e2039.

110. Liu X, Tong J, Zweier JR, Follmer D, Hemann C, Ismail RS, et al. Differences in oxygen-dependent nitric oxide metabolism by cytoglobin and myoglobin account for their differing functional roles. FEBS J 2013;280:3621-3631.

111. Reeder BJ, Ukeri J. Strong modulation of nitrite reductase activity of cytoglobin by disulfide bond oxidation: Implications for nitric oxide homeostasis. Nitric Oxide 2018;72:16-23.

112. Jourd'heuil FL, Xu H, Reilly T, McKellar K, El Alaoui C, Steppich J, et al. the hemoglobin homolog cytoglobin in smooth muscle inhibits apoptosis and regulates vascular remodeling. Arterioscler Thromb Vasc Biol 2017;37:1944-1955.

113. Van Thuy TT, Thuy LT, Yoshizato K, Kawada N. Possible involve- ment of nitric oxide in enhanced liver injury and fibrogenesis during cholestasis in cytoglobin-deficient mice. Sci Rep 2017;7:41888.

114. Friedman SL. Hepatic stellate cells: protean, multifunctional, and enigmatic cells of the liver. Physiol Rev 2008;88:125-172.

115. Blaner WS, O'Byrne SM, Wongsiriroj N, Kluwe J, D'Ambrosio DM,

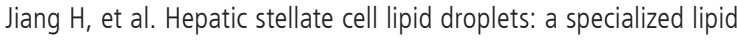
droplet for retinoid storage. Biochim Biophys Acta 2009;1791:467473.

116. Bataller R, Brenner DA. Liver fibrosis. J Clin Invest 2005;115:209218

117. Sachs BD, Baillie GS, McCall JR, Passino MA, Schachtrup C, Wallace DA, et al. p75 neurotrophin receptor regulates tissue fibrosis through inhibition of plasminogen activation via a PDE4/CAMP/ PKA pathway. J Cell Biol 2007;177:1119-1132.

118. Senoo H, Kojima N, Sato M. Vitamin A-storing cells (stellate cells). Vitam Horm 2007;75:131-159.

119. Senoo H, Hata RI, Nagai Y, Wake K. Stellate cells (vitamin A-storing cells) are the primary site of collagen synthesis in non-parenchymal cells in the liver. Biomed Res 1984;5:451-458.

120. Friedman SL, Roll FJ, Boyles J, Bissell DM. Hepatic lipocytes: the principal collagen-producing cells of normal rat liver. Proc Natl Acad Sci U S A 1985;82:8681-8685.

121. Yokoi Y, Namihisa T, Kuroda H, Komatsu I, Miyazaki A, Watanabe $S$, et al. Immunocytochemical detection of desmin in fat-storing cells (Ito cells). Hepatology 1984;4:709-714.

122. Reeves HL, Friedman SL. Activation of hepatic stellate cells--a key issue in liver fibrosis. Front Biosci 2002;7:d808-d826.

123. Milani S, Herbst H, Schuppan D, Kim KY, Riecken EO, Stein H. Procollagen expression by nonparenchymal rat liver cells in experimental biliary fibrosis. Gastroenterology 1990;98:175-184.

124. Marra F. Hepatic stellate cells and the regulation of liver inflammation. J Hepatol 1999;31:1120-1130.

125. Heymann F, Tacke F. Immunology in the liver--from homeostasis to disease. Nat Rev Gastroenterol Hepatol 2016;13:88-110.

126. Pellicoro A, Ramachandran P, Iredale JP, Fallowfield JA. Liver fibrosis and repair: immune regulation of wound healing in a solid organ. Nat Rev Immunol 2014;14:181-194.

127. Brenner C, Galluzzi L, Kepp O, Kroemer G. Decoding cell death signals in liver inflammation. J Hepatol 2013;59:583-594.

128. Paik YH, Iwaisako K, Seki E, Inokuchi S, Schnabl B, Osterreicher $\mathrm{CH}$, et al. The nicotinamide adenine dinucleotide phosphate oxidase (NOX) homologues NOX1 and NOX2/gp91(phox) mediate hepatic fibrosis in mice. Hepatology 2011;53:1730-1741.

129. Paik Y-H, Brenner DA. NADPH oxidase mediated oxidative stress in hepatic fibrogenesis. Clin Mol Hepatol 2011;17:251-257.

130. Bataller R, Schwabe RF, Choi YH, Yang L, Paik YH, Lindquist J, et al. NADPH oxidase signal transduces angiotensin II in hepatic stellate cells and is critical in hepatic fibrosis. J Clin Invest 2003;112:1383-1394. 
131. Dooley S, ten Dijke P. TGF- $\beta$ in progression of liver disease. Cell Tissue Res 2012;347:245-256.

132. Trautwein C, Friedman SL, Schuppan D, Pinzani M. Hepatic fibrosis: Concept to treatment. J Hepatol 2015;62:S15-S24.

133. Kocabayoglu P, Lade A, Lee YA, Dragomir A-C, Sun X, Fiel MI, et al. $\beta$-PDGF receptor expressed by hepatic stellate cells regulates fibrosis in murine liver injury, but not carcinogenesis. J Hepatol 2015;63:141-147.

134. Wilhelm A, Aldridge V, Haldar D, Naylor AJ, Weston CJ, Hedegaard $D$, et al. CD248/endosialin critically regulates hepatic stellate cell proliferation during chronic liver injury via a PDGF-regulated mechanism. Gut 2016;65:1175-1185.

135. Hauff P, Gottwald U, Ocker M. Early to Phase II drugs currently under investigation for the treatment of liver fibrosis. Expert Opin Investig Drugs 2015;24:309-327.

136. Lipson KE, Wong C, Teng Y, Spong S. CTGF is a central mediator of tissue remodeling and fibrosis and its inhibition can reverse the process of fibrosis. Fibrogenesis Tissue Repair 2012;5(Suppl 1):S24.

137. Fuchs BC, Hoshida Y, Fujii $T$, Wei L, Yamada S, Lauwers GY, et al. Epidermal growth factor receptor inhibition attenuates liver fibrosis and development of hepatocellular carcinoma. Hepatology 2014;59:1577-1590.

138. Lanaya H, Natarajan A, Komposch K, Li L, Amberg N, Chen L, et al. EGFR has a tumour-promoting role in liver macrophages during hepatocellular carcinoma formation. Nature Cell Biology 2014;16:972981.

139. Liu X, Xu J, Rosenthal S, Zhang LJ, McCubbin R, Meshgin N, et al. Identification of lineage-specific transcription factors that prevent activation of hepatic stellate cells and promote fibrosis resolution. Gastroenterology 2020;158:1728-1744.e14.

140. Yan K, Deng $X$, Zhai $X$, Zhou M, Jia X, Luo L, et al. p38 mitogenactivated protein kinase and liver $x$ receptor-a mediate the leptin effect on sterol regulatory element binding protein-1c expression in hepatic stellate cells. Mol Med 2012;18:10-18.

141. Beaven SW, Wroblewski K, Wang J, Hong C, Bensinger S, Tsukamoto $H$, et al. Liver $X$ receptor signaling is a determinant of stellate cell activation and susceptibility to fibrotic liver disease. Gastroenterology 2011;140:1052-1062.

142. Zhou Y, Jia X, Qin J, Lu C, Zhu H, Li X, et al. Leptin inhibits PPARY gene expression in hepatic stellate cells in the mouse model of liver damage. Mol Cell Endocrin 2010;323:193-200.

143. De Minicis S, Seki E, Oesterreicher C, Schnabl B, Schwabe RF, Brenner DA. Reduced nicotinamide adenine dinucleotide phosphate oxidase mediates fibrotic and inflammatory effects of leptin on hepatic stellate cells. Hepatology 2008;48:2016-2026.

144. Chandrashekaran V, Das S, Seth RK, Dattaroy D, Alhasson F, Michelotti $G$, et al. Purinergic receptor X7 mediates leptin induced GLUT4 function in stellate cells in nonalcoholic steatohepatitis.
BBA-Mol Basis Dis 2016;1862:32-45.

145. Lan T, Kisseleva T, Brenner DA. Deficiency of NOX1 or NOX4 Prevents Liver Inflammation and Fibrosis in Mice through Inhibition of Hepatic Stellate Cell Activation. PLoS One 2015;10:e0129743.

146. Liu Z, Li C, Kang N, Malhi H, Shah VH, Maiers JL. Transforming growth factor $\beta$ (TGF $\beta$ ) cross-talk with the unfolded protein response is critical for hepatic stellate cell activation. J Biol Chem 2019;294:3137-3151.

147. Khomich O, Ivanov AV, Bartosch B. Metabolic hallmarks of hepatic stellate cells in liver fibrosis. Cells 2019;9:24.

148. Issa R, Williams E, Trim N, Kendall T, Arthur MJ, Reichen J, et al. Apoptosis of hepatic stellate cells: involvement in resolution of biliary fibrosis and regulation by soluble growth factors. Gut 2001;48:548-557.

149. Kisseleva T, Cong M, Paik Y, Scholten D, Jiang C, Benner C, et al. Myofibroblasts revert to an inactive phenotype during regression of liver fibrosis. Proc Natl Acad Sci U S A 2012;109:9448-9453.

150. El Taghdouini A, Najimi M, Sancho-Bru P, Sokal E, van Grunsven $L A$. In vitro reversion of activated primary human hepatic stellate cells. Fibrogenesis Tissue Repair 2015;8:14.

151. Kong $X$, Feng D, Wang H, Hong F, Bertola A, Wang FS, et al. Interleukin-22 induces hepatic stellate cell senescence and restricts liver fibrosis in mice. Hepatology 2012;56:1150-1159.

152. Nishizawa H, Iguchi G, Fukuoka H, Takahashi M, Suda K, Bando H, et al. IGF-I induces senescence of hepatic stellate cells and limits fibrosis in a p53-dependent manner. Sci Rep 2016;6:34605.

153. Nishi H, Inagi R, Kawada N, Yoshizato K, Mimura I, Fujita T, et al. Cytoglobin, a novel member of the globin family, protects kidney fibroblasts against oxidative stress under ischemic conditions. Am J Pathol 2011;178:128-139.

154. Stone LC, Thorne LS, Weston CJ, Graham M, Hodges NJ. Cytoglobin expression in the hepatic stellate cell line HSC-T6 is regulated by extracellular matrix proteins dependent on FAK-signalling. Fibrogenesis Tissue Repair 2015;8:15.

155. Wei H, Lin L, Zhang X, Feng Z, Wang Y, You Y, et al. Effect of cytoglobin overexpression on extracellular matrix component synthesis in human tenon fibroblasts. Biol Res 2019;52:23.

156. Randi EB, Vervaet $B$, Tsachaki M, Porto E, Vermeylen S, Lindenmeyer MT, et al. The antioxidative role of cytoglobin in podocytes: implications for a role in chronic kidney disease. Antioxid Redox Signal 2020;32:1155-1171.

157. Thi Thanh Hai N, Thuy LTT, Shiota A, Kadono C, Daikoku A, Hoang $D V$, et al. Selective overexpression of cytoglobin in stellate cells attenuates thioacetamide-induced liver fibrosis in mice. Sci Rep 2018:8:17860.

158. Fermi G, Perutz MF, Shaanan B, Fourme R. The crystal structure of human deoxyhaemoglobin at $1.74 \mathrm{~A}$ resolution. J Mol Biol 1984;175:159-174. 
Le Thi Thanh Thuy, et al.

Cytoglobin suppresses HSC activation and fibrosis

159. Pesce A, Dewilde S, Nardini M, Moens L, Ascenzi P, Hankeln T, et al. Human brain neuroglobin structure reveals a distinct mode of controlling oxygen affinity. Structure 2003;11:1087-1095.
160. Hubbard SR, Hendrickson WA, Lambright DG, Boxer SG. X-ray crystal structure of a recombinant human myoglobin mutant at 2.8 A resolution. J Mol Biol 1990;213:215-218. 